\title{
Por QUe ESTUdAR A ANTIGUIDADE DA PENÍNSULA IBÉRICA No BRASIL?
}

Why to study the ancient Iberian Peninsula in BRazil?

\author{
Pedro Paulo Abreu Funari * \\ rdasilva@unicamp.br \\ Filipe Noé Silva** \\ filipe.hadrian@gmail.com
}

RESUMO: O artigo inicia-se com a pergunta, porque estudar a Antiguidade da Península Ibérica no Brasil? Apresenta-se a perspectiva adotada, fundada na História Externalista da Ciência. Em seguida, é apresentada a trajetória histórica brasileira, em particular do ensino e estudo da História. Ressaltase a relevância da História Ibérica para entender a sociedade brasileira, em sua trajetória: o predomínio da língua latina; características culturais tão importantes como o patrimonialismo, o compadrio e as formas de subordinação social; a mescla étnica, cultural e religiosa. Conclui-se pela importância do ensino e da pesquisa sobre a Antiguidade da Península Ibérica.

PalaVRas Chave: Península Ibérica, Ensino de História, História Antiga

ABSTRACT: This paper starts with the question: why to study the Ancient Iberian Peninsula in Brazil? Firstly, this study adopts an externalist viewpoint of the science, a perspective that recognizes the importance of social and historical contexts in guiding the academic research. Secondly, we present a brief narrative about the History teaching in Brazil. In this account, the History of Iberian Peninsula is emphasized as fundamental for a better understanding of Brazilian society.

KEYWORDS: Iberian Peninsula, History teaching, Ancient history.

\section{Introdução: o presentismo}

Vivemos um predomínio da preocupação com o presente, como nos alerta o historiador François Hartog (2003). O estudioso francês relaciona isso ao fim da Guerra Fria e um abrandamento do Estado Nacional, fundado na invenção de um passado para se busque outro futuro. Nos últimos anos, contudo, houve um recrudescimento do nacionalismo (GROSBY, 2005) que questiona essa assertiva de Hartog, ao recolocar a nação e, assim, a invenção de um passado compartilhado. Mesmo assim, a ênfase no presente tem se acentuado pelo avanço tecnológico, pela rapidez e ubiquidade do contato virtual (MCLUHAN 1964; GERNAOUTI-HELI, 1999). Isto significa que o utilitarismo e o imediatismo difundem-se como critérios sociais, por meio do presentismo (HARTOG, 2003).

\footnotetext{
* Doutor em Arqueologia pela USP, Livre-docente em História e Professor Titular pela Unicamp. Estágios pósdoutorais em: Stanford University/Estados Unidos; Durham University/Inglaterra; Université de Paris $X$, Nanterre, Paris X/França; Universitat de Barcelona/Espanha; University College London/Grã-Bretanha.

${ }^{* *}$ Doutorando em História pela Universidade de Campinas.
} 


\section{O estudo de História e o presentismo}

Essas tendências afetam em particular o ensino, a pesquisa e o estudo da História. Há dois aspectos desse imediatismo, um na sociedade, em geral, e outro no campo da História, como atividade profissional. No primeiro caso, a valorização de tudo que tenha aplicação no quotidiano, em particular para dominar melhor o mundo, só tem aumentado (SALAZAR-ACOSTA, 2008). Basta lembrar que a China, nas últimas décadas dedicou-se a esse domínio científico, tecnológico e técnico, inclusive pelo incentivo concentrado nas ciências duras e na formação no estrangeiro (FUNARI et al, 2013). A segunda potência econômica mundial atesta a força do pragmatismo, da ênfase tecnológica e fundada na essência do capitalismo: a destruição criativa (schöpferische Zerstörung): Dieser Prozess der schöpferischen Zerstörungist das für den Kapitalismus wesentliche Faktum (SCHUMPETER, 2005, p. 137 - "este processo de destruição criativa é um fato essencial do Capitalismo"). Entre as consequências, as disciplinas práticas ganham relevância tanto na educação básica quanto na universitária.

No âmbito das Humanidades, assediadas pelas forças do pragmatismo e do utilitarismo, a reação frequente tem sido a defesa da sua relevância para o presente. Algumas disciplinas já surgiram nessa direção, como a Sociologia, a Psicologia ou a Ciência Política. Já a História, por definição voltada para o passado, mesmo quando trata do Tempo Presente, abrigou-se no estudo do que ocorreu no passado a serviço do presente, com estudos de recepção e usos do passado (SETTIS, 2006). O Estado Nacional centrou sua atenção no relato genealógico da nação, como no caso bem conhecido e paradigmático dos supostos ancestrais gauleses, na França, às expensas das múltiplas outras raízes, romanas, germânicas, sarracenas, entre outras. Isso é de particular relevância nos ensinos fundamental e médio, como no caso extremo dos Estados Unidos, cuja História se resume à experiência americana (American experience), de costa a costa (from Coast to Coast), até mesmo em licenciaturas, cujos currículos tocam o resto do mundo apenas na medida em que foram encontrados pela nação americana.

\section{O Brasil e a educação}

No caso do Brasil, o foco na nação também está presente, e o utilitarismo capitalista tem levado, repetidas vezes, a adequar o currículo à formação para o mercado de trabalho 
(GERMANO, 1994). Disso resultou a retirada de inúmeras disciplinas, do latim à educação musical, da Filosofia ao francês, e mesmo algumas louváveis iniciativas de formação humanística para o trabalho não foram implementadas, como no caso do castelhano, que deveria ter se generalizado desde o governo Sarney, na década de 1980.

No âmbito universitário, a pós-graduação, ao estruturar-se, desde a década de 1970, abriu possibilidades de crescente diversificação e especialização (BORTOLANZA, 2017). Nas Humanidades, isso significou crescimento sistemático, regular e sustentado de uma formação almejando a inserção na ciência global, sem limites. O apoio do CNPq, Capes e Fundações de apoio à pesquisa nos Estados, (como a Fapesp, a Fapemig e as outras), tem sido consistente e cada vez mais voltado para a interação universal. Áreas de pesquisa antes inexistentes floresceram, como Linguística, Hebraico, Russo, História da América Espanhola, História da África; outras multiplicaram-se, como História Antiga, Arqueologia Clássica, PréHistória, Arqueologia Histórica, Literaturas várias, estudos literários, entre outros.

O horizonte da nação continua a ser sempre muito dominante, como mostra o predomínio de áreas como História do Brasil, Geografia do Brasil, Língua Portuguesa no Brasil e Literatura Brasileira, para citar alguns mais evidentes. Contudo, a formação em Mestrado, Doutoramento de Pós-Doutoramento tem incluído áreas como Estudos Celtas, Arqueologia Pré-Colombiana, Literaturas Africanas e Estudos Orientais. Entre as consequências da formação de quadros qualificados, estiveram a criação de cursos ministrados por especialistas nos temas, algo antes raro, assim como de programa de PósGraduação abrigando essas áreas, pelo Brasil afora, (como o Mestrado Profissional em História Ibérica na Unifal/MG, por exemplo).

Isto posto, a legítima questão sobre a relevância de tais estudos especializados continua a ser colocada, ainda mais em tempos de imediatismos nacionalistas ou populistas. As recentes controvérsias sobre a Base Nacional Comum Curricular atestam essas tensões (FUNARI, 2016), como no caso paradigmático da tentativa de abandono de autores estrangeiros como o moçambicano Mia Couto ou o português Fernando Pessoa (MOREIRA, 2016). Ainda que isso tenha sido revertido, importa ressaltar essa tendência, há tantas décadas, nacionalista e populista, contra tudo que desvia do hic et nunc, do aqui e agora do mercado de trabalho para a raia miúda. Como dito, assim se sacrificou no Ensino Fundamental, o francês, na década de 1970, o latim, no início dos 1960, e agora iriam pelo 
mesmo caminho grande parte da História da Humanidade, continentes inteiros. Portanto, sempre cabe esmiuçar a questão da relevância da formação de repertório cultural para os futuros cidadãos, para além da preparação e adestramento tacanho de uma mão de obra subserviente, passiva, complacente e sujeita à manipulação.

\section{A história da Península Ibérica}

Qual o papel da História Ibérica, neste contexto? O período moderno é o mais conhecido, na medida em que o Brasil e o que viria a ser a América Latina foram colônias ibéricas por mais de três séculos. A Antiguidade e a Idade Média têm tido atenção crescente na pós-graduação, na pesquisa acadêmica em geral, com resultados positivos para os Ensinos Fundamental e Médio. Isso é de particular relevância para Língua e Literatura e para a História, neste caso bem relacionadas e imbricadas e, por isso mesmo, convém iniciar-se o estudo do tema por essa interface.

O latim está no centro disso, como fica óbvio no conceito mesmo de América Latina (HEYDENREICH, 1995). Trata-se da língua e literatura latinas antigas, mas também das línguas românicas em geral, e da Península Ibérica, com destaque para o Português e o Castelhano e suas literaturas. A História faz-se com documentos lidos e compreendidos no original, motivo pelo qual esse conhecimento do latim, do galego-português e do castelhano é fundamental também para a História. A disseminação de conceitos básicos para os alunos ajuda a formar uma cidadania bem informada e crítica. Não à toa o Auto da Barca do Inferno (1531), de Gil Vicente (1465-1536), com sua crítica social e referências clássicas como Luciano e seu Diálogo dos Mortos (século II d.C.), é presença recorrente nas leituras escolares e para uma leitura fundamentada há necessidade de tratar do latim (e do grego!), da mitologia antiga, das literaturas ibéricas, da História Medieval Ibérica e muito mais. Somos todos prisioneiros da nossa língua (STEWARD, 1988) e uma reflexão sobre isso é ponto de partida fundamental e o conhecimento desses legados ibéricos: latim (e grego!), português (BUENO, 1967), castelhano, ao menos.

Em seguida, há características culturais que não se desvinculam da Península Ibérica, como o patrimonialismo (FAORO, 1976), o compadrio (DA MATTA, 1990) e as formas de subordinação social (clientelismo, caciquismo/caudilhismo). Não há consenso entre os estudiosos sobre a importância desses aspectos culturais, frente, em particular, à onipotência do capitalismo, que domina as relações sociais dos Estados Unidos à China 
(WOLF, 1984; HUNG, 2009). E, de fato, essas relações econômicas e materiais predominantes organizam nosso mundo e daí que essas interpretações transculturais sejam mesmo relevantes (FOUCAULT, 2004). Mesmo assim, as especificidades culturais constituem elementos fundamentais da vida social, como atestam a Antropologia Cultural (BOAS, 1940), a História Cultural (ORY, 2004) ou a Semiótica (LAgOPoulos, 2010). Neste sentido, o patrimonialismo, o compadrio, o clientelismo, o caciquismo, a distinção social (estamental), são aspectos da sociabilidade (NAVARRO NAVARRO 2006) de matriz secular ibérica (WECKMANN, 1992; 1993; ROMANO, 1984). Claro, esses aspectos não podem ser separados tanto das matrizes indígenas e afro-americanas, quanto das forças do capitalismo, mas não se pode prescindir desse vínculo ibérico (antigo e medieval). O mundo material está carregado de iberismo (CONTIN, 1996; FUNARI, 2015). Motivo adicional para a atenção à História Ibérica.

Mais que tudo, talvez, a mescla étnica, cultural e religiosa, deva ser relacionada à Península Ibérica (ANDRADE FILHO, 1989; GONZÁLEZ FERRÍN, 2017). Isso não é apanágio ibérico. O mundo romano é exemplo direto disso (WEBSTER, 2001), mas outros tantos, com conexão mais indireta podem ser mencionados, como a civilização otomana. No nosso caso, contudo, aquilo que seria chamando por Fernando Ortiz (1983) de Transculturação relaciona-se a essas experiências ibéricas, fecundadas no contexto americano. Conceitos correlatos de miscigenação, mestiçagem (GRUZINSKI, 1999), creolização, hibridismo (GARCÍA CANCLINI, 1989), sincretismo (CHEVITARESE; CORNELLI, 2009), fluidez (NOGUEIRA, FUNARI; COLLINS, 2010) e convivência (MANN et al, 1992), assim como outras menos generosas, como conversão, conquista/reconquista (BOISSELIER, 1994) e aculturação (REDFIED et al, 1936) relacionam-se, também, às matrizes ibéricas antigas e medievais.

\section{A experiência da Roma Imperial como paradigma}

Após unificar o território da Itália sob o seu domínio, Roma assumiu o controle sobre vários territórios do Mediterrâneo desde meados de III a.C. e durante os imediatos séculos seguintes. Em meio à oscilação entre períodos em que a anexação territorial no imperium sine fine foi levada a cabo de maneira quase ininterrupta, mas também longos períodos de paz e de renúncia de territórios conquistados, tem-se reconhecido que boa parte da anexação de povos e regiões localizados na Península Balcânica, na Síria, na Península Ibérica e no norte da África, se concretizou a partir de campanhas militares 
romanas ainda durante o período republicano (KELLY, 2006, p. 6), e perdurou até a época de Trajano: o muro erigido na Bretanha pelo imperador Adriano não deixa dúvidas quanto à ruptura com a postura de um Império expansionista.

Ocorreram a construção de cidades e a transposição das leis romanas, distribuídas em território ibérico de maneira hierarquizada e conforme as características de cada região. Como demonstrou Julio Mangas (2001), a Península Ibérica, desde à época do ditador Júlio César, foi ocupada por 399 cidades romanas distintas, e classificadas como “(...) colonias romanas ou latinas, municipios romanos o latinos, ciudades federadas, ciudades libres y ciudades estipendiarias" (MANGAS, 2001, p. 10). A redefinição geográfica e administrativa dos territórios ibéricos promovida sob Augusto, por sua vez, significou uma ruptura com um período marcado por embates bélicos e dado início a uma experiência imperial na qual as populações locais passariam a conviver, a partir de então, sob a influência (sobretudo jurídica e cultural) dos romanos (KEAY, 2000, p. 132).

Desde o século XIX, o processo de expansão imperial ficou conhecido na historiografia especializada como Romanização: sob a influência do neocolonialismo de seu próprio tempo, o referido conceito, pensado em termos de civilização versus barbárie, passou a ser empregado com o intuito de justificar, com base na experiência histórica dos antigos romanos em suas províncias, a ação imperialista europeia sobre a África, a Ásia e a América Latina. Como destacou Richard Hingley:

A definição de 'barbárie' à sociedade colonizada pelos seus senhores romanos foi usada para dar uma justificativa direta para a dominação política, militar e territorial desses povos, por meio do argumento de que o controle imperial permitia a transmissão de uma civilização superior a povos culturalmente inferiores. (...) Essa ideia poderosa foi recebida e transformada pelas potências ocidentais durante o século XIX, para justificar relações imperiais (HINGLEY, 2010, p. 70).

Em resposta às exigências epistemológicas demandadas pela História e pela Arqueologia ao longo do século XX, no entanto, a proposta de missão civilizatória subjacente ao conceito de Romanização, assentado sobre uma ideia de aculturação dos povos conquistados por Roma, tem sido avaliada de maneira crítica desde o início das teorias chamadas pós-colonialistas no âmbito das Ciências Sociais.

Destituídas do teor colonial no qual "superiores conquistam inferiores", as narrativas históricas pós-colonialistas, ao contrário, vislumbram a possibilidade de 
reescrever a História do Império Romano por meio de conceitos que ressaltam os intercâmbios étnicos e culturais impulsionados pela experiência imperial romana, tais como: hibridização, mestiçagem e creolização (FUNARI; GRILLO, 2014, p. 210; FUNARI; GARRAFFONI, 2018, p. 250). Ainda que manifeste ressalvas às teorias pós-coloniais, o arqueólogo Chris Gosden (2004), em seu livro Archaeology and colonialism, apresentou uma perspectiva similar, e defendeu que as experiências coloniais teriam propiciado encontros culturais entre os povos envolvidos nesta experiência histórica:

Vejo, talvez de maneira paradoxal, o colonialismo como uma fonte de criatividade e experimentação. Ainda que muitas vezes dolorosos, os encontros coloniais causam a dissolução de valores nos dois lados e criam modos novos de fazer as coisas (nos sentidos material e social). Insistir no tema da criatividade nos afasta de noções como impacto fatal, dominação e resistência, centro e periferia, enfatizando que as culturas coloniais são criadas por todos aqueles que delas participam, de modo que todas elas possuem agência e efeito social, e que colonizador e colonizado, igualmente, são transformados, de forma radical, por esta experiência (GOSDEN, 2004, p. 25, tradução nossa ${ }^{1}$ ).

Em consonância com esses referenciais, portanto, pode-se reinterpretar os processos de integração provincial à dinâmica imperial romana sem recorrer à problemática noção de aculturação que outrora embasou as teorias de romanização. A seguir, a análise de uma inscrição ${ }^{2}$ oriunda da antiga cidade de Bracara Augusta, situada no Noroeste Lusitano, tornará patente os méritos das teorias pós-coloniais na feitura de uma História sobre o Império Romano desprovida do teor imperialista presente na documentação antiga e na historiografia moderna (marcada pela experiência neocolonial).

\footnotetext{
${ }^{1}$ No original: "Paradoxically, perhaps, I see colonialism as often being a source of creativity and experiment, and while certainly not being without pain, colonial encounters cause the dissolution of values on all sides, creating new ways of doing things in a material and social sense. A stress on creativity takes us away from notions such as fatal impact, domination and resistance or core and periphery, emphasizing that colonial cultures were created by all who participated in them, so that all had agency, and social effect, with coloniser and colonised alike being radically changed by the experience" (GOSDEN, 2004, p. 25).

${ }^{2}$ AE 1973, 297. Disponível em:< http://edabea.es/pub/record_card_1.php?rec=6522\&newlang=en>. Acesso em: 20 jun. 2019.
} 


\section{Transcrição:}

C(aius) IVLIVS

[P]INTAMI

LIBERTVS

PVDE(N)S

H(ic) S(itus) E(st)

\section{Tradução:}

Aqui jaz Caio Júlio Pudens, o liberto de Píntamo.

AE 1973, 297.

Imagem 01: Monumento Sepulcral do liberto Caio Júlio Pudens. Século I d.C. Museu Regional de Arqueologia D. Diogo de Sousa. Braga, Portugal. Foto: Paula Funari. Acervo Pessoal.

Em geral, se reconhece que os primeiros contatos entre os romanos e os habitantes da região bracaraugustana ocorreram em meados do século II antes de nossa era, decorrente da expedição promovida por Décimo Júnio Bruto, entre os anos de 138 e 136 a.C. (MARTINS; CARVALHO, 2016, p. 221). Também parece consensual que a fundação de Bracara Augusta deriva da reorganização provincial promovida por Otávio Augusto (com a criação das Hispaniae Ulterior, Citerior e da Lusitânia) $)^{3}$. A partir da Arqueologia, admite-se que a cidade "(...) já existiria por volta dos anos $3 / 2$ a.C (...) com capacidade para se expressar em atos de caráter cívico, designadamente, através da construção de monumentos em honra de Augusto" (MARTINS; CARVALHO, 2016, p. 224).

Embora constituam partes de um processo paulatino e variável entre as distintas regiões da Península Ibérica (Cf. ALFÖLDY, 1996), a fundação de cidades, principalmente nas condições de municipia e coloniae, a transposição do direito latino a essas mesmas

\footnotetext{
${ }^{3}$ De acordo com Jorge Alarcão (1988, p. 13), o início da “missão” romana na Península Ibérica, em geral, teria se iniciado no ano de 218 antes da Era Comum. O autor reconhece que a divisão da Hispania em três províncias, teria ocorrido no ano de 27 a.C. (ALARCÃO, 1988, p. 37).
} 
comunidades, além da própria concessão da cidadania romana às elites locais, viabilizaram o contato cultural entre o modo de vida trazido pelos romanos e as formas sociais locais préromanas: daí a ideia de uma progressiva Romanização dos povos ibéricos.

Se, por um lado, é inegável que a conquista romana modificou profundamente as relações sociais e materiais dos povos ibéricos (Cf. KEAY, 1998), por outro lado, em contrapartida, a ideia de uma aculturação das populações locais, sempre pensada em benefício de uma suposta cultura romana homogênea e superior, não nos parece suficiente para a compreensão de “(...) realidades heterogêneas, conflitivas e diversas, contendo relações e interações fluidas" (FUNARI; GARRAFFONI, 2018, p. 250). Tampouco a adesão à língua latina, cujo uso nas províncias ibéricas é atestado por milhares de inscrições, pode ser interpretada desde uma perspectiva de sobreposição cultural.

A partir de uma assertiva do geógrafo Estrabão (Geografia. III. 2. 15) ${ }^{4}$, tem-se reconhecido que o predomínio da língua latina ocorreu sobretudo na região sul da Península Ibérica, onde a transformação urbana e cultural promovida pelos romanos, segundo o relato do geógrafo, se desenvolveu de maneira mais precoce e intensa. Cidades importantes da Baetica como Carteia, Gades, Hispalis e Córduba, fundadas ainda no período republicano, seriam exemplos incontestes de que parte significativa de integração política e econômica à lógica imperial promovida pelos romanos (KEAY, 1998, p. 65; REMESAL, 2011). No norte peninsular, em contraste, a permanência de elementos linguísticos pré-romanos continuaria visível, conforme demonstrado nos estudos de Amílcar Guerra (2016, p. 50), na própria toponomástica antiga, mas também na própria composição onomástica da local.

Conservada no atual Museu Regional de Arqueologia D. Diogo de Sousa (Braga, Portugal), a estela sepulcral do liberto Caio Júlio Pudens (Imagem 01), feita sob as

\footnotetext{
4 “A prosperidade da região veio acompanhada para os Turdetanos do progresso civilizacional e político, e também para os Célticos, devido à sua vizinhança - segundo diz Políbio, por causa do parentesco -, mas para estes em menor escala (pois a maior parte deles continua a viver em aldeias). Contudo, os Turdetanos, e sobretudo os que vivem em redor do Bétis, adoptaram por inteiro o estilo de vida dos Romanos, nem sequer se recordando já da sua própria língua. Na sua maioria, tornaram-se Latinos e receberam Romanos como colonos, de modo que pouco <lhes> falta para serem todos Romanos. E as cidades agora povoadas de forma mista, Pax Augusta entre os Célticos, Augusta Emerita entre os Túrdulos, Caesaraugusta na região dos Celtiberos e algumas outras colónias evidenciam a transformação das mencionadas formas de vida cívica. E todos os Iberos que adoptaram este modelo são denominados togati (entre eles estão também os Celtiberos, que outrora eram considerados como os mais selvagens de todos). É isto o que há a dizer sobre os Turdetanos” (ESTRABÃO. Geografia. III. 2.15. Editora da Universidade de Coimbra, 2016. Tradução de Jorge Deserto e Susana da Hora Marques Pereira.).
} 
dimensões de 1,84m (altura) x 0,475m (largura) x 0,145m (espessura), apresenta, conforme já destacaram P. Le Roux e Alain Tranoy (1973, p. 184-186), características referentes à miscelânea (étnica, cultural e social) entre os romanos e a população originária da região de Bracara Augusta. Este atributo pode ser observado, por exemplo, na palavra Pintami (flexionada para o caso genitivo de Pintamus) registrada no monumento funerário. Em primeiro lugar, deve-se destacar que o nome "Pintamus" é nativo, e teria a sua origem na onomástica das populações indígenas do território lusitano (LE ROUX; TRANOY, 1973, p. 185; REDENTOR, 2011).

Em segundo lugar, também é observável que a inscrição apresenta apenas o cognomen do patrono: ao contrário do que acontece com o liberto Caio Júlio Pudens, cujo nome fora grafado, nesta estela funerária (e de maneira pouco usual), sob uma configuração trinominal. Por um lado, a escolha de reservar os tria nomina ao indivíduo egresso da servidão pode ter tido como objetivo principal o destaque à condição de liberdade de Caio Júlio Pudens ${ }^{5}$. Neste caso, é provável que o patrono do ex-escravo se chamasse Caius Iulius Pintamus (REDENTOR, 2011, p. 295). Por outro lado, se considerarmos que a estrutura nominal dos indígenas ibéricos difere da romana, e é formada por “(...) um modelo local de nome único seguido de patronímico" (Cf. GUERRA, 2016, p. 55), poder-se-ia, ademais, conjecturar a permanência não apenas etimológica de elementos pré-romanos na epigrafia latina provincial, mas também a própria manutenção da configuração onomástica nativa sob o domínio imperial romano.

A rejeição a um modelo interpretativo centrado apenas no conceito de aculturação (Cf. FUNARI; GARRAFFONI, 2018), portanto, aproxima-nos de toda a complexidade inerente às trocas, imposições e resistências subjacentes ao encontro entre povos distintos. Antigos, modernos ou contemporâneos, como destacou Gosden $\left(2004\right.$, p. 5) ${ }^{6}$, os contatos culturais constituem, antes de qualquer coisa, um fato humano básico.

\footnotetext{
${ }^{5}$ Sobre a composição do nome dos libertos, Jean-Marie Lassère salienta que:"Plus tard, à la fin de la République et sous l'Empire, la séquence onomastique de l'affranchi comporte généralement le prénom et le nom gentilice de son ancient maître, puis, à l'instar de la filiation pour les ingénus, la libertinatio, qui s'indique par réference au prénom du patronus - il est inutile répeter le gentilice -, et enfin un cognomen, qui est l'ancien nom d'esclave” (LASSERE, 2005, p. 159).

${ }^{6}$ Parafraseado do original: “Culture contact is a basic human fact” (GOSDEN, 2004, p. 5).
} 


\section{Conclusão: a importância de uma História Ibérica}

Nestas circunstâncias, a importância do ensino e da pesquisa sobre as Antiguidades (da Pré-História à época moderna) da Península Ibérica fica evidente. O Programa de PósGraduação em História Ibérica da Unifal/MG, Mestrado Profissional, centrado na qualificação de docentes do Ensino Fundamental II e Médio, responde a esta sentida demanda de formação de quadros qualificados, para a formação da cidadania.

A participação de docentes de outras universidades no Programa também demonstra o interesse despertado pelo tema ibérico e augura a difusão da pesquisa e do ensino sobre História Ibérica. O primeiro catedrático do Brasil de História Antiga e Medieval, Euripedes Simões de Paula (SILVA, 2009), escreveu sua tese de cátedra sobre Marrocos $e$ suas relações com a Ibéria na Antiguidad (1946, publicada em 1973), que já tratava de alguns dos temas mencionados acima, na terminologia da época, claro. Como ressaltou Manuel Azanã: "Las formas sociales y políticas en las que los pueblos pueden entrar y permanecer, no están sujetas a su arbitrio, sino determinadas por su carácter y su pasado" (SANTOS JULIÁ, 2012). Para uma melhor compreensão de nossa própria História, portanto, não se pode deixar de perscrutar a História Ibérica.

\section{REFERÊNCIAS BIBLIOGRÁFICAS}

ALARCÃO, J. O Domínio Romano em Portugal. Mem Martins: Publicações Europa-América, 1988.

ALFÖLDY, G. A história social de Roma. Lisboa: Editorial Presença, 1989.

ALFÖLDY, G. Spain. In: BOWMAN, A. et al. The Cambridge Ancient History. vol. X. 2 ed. Cambridge: University Press, 1996, p. 449-463.

ANDRADE FILHO, R. Os muçulmanos na Península Ibérica. São Paulo: Contexto, 1989.

BOAS, F. Race, Language, and Culture, 1940.

BOISSELIER, S. Réflexions sur l'idéologie portugaise de la Reconquête, XII-XIVe. siècles. Mélanges de la Casa de Velazquez, 30, 1994, p. 139-165.

BORTOLANZA, J. Trajetória do Ensino Superior Brasileiro. Uma busca da origem até a atualidade. XVII Colóquio Internacional de Gestion Universitaria, 2017, Mar del PIta. XVII Coloquio Internacional de Gestio Universitária. Mar del Plata, 2017.

BUENO, S. A formação histórica da Língua Portuguesa. São Paulo: Saraiva, 1967.

CANCLINI, N. G. Culturas híbridas: Estrategias para entrar y salir de la modernidad [Hybrid cultures: Strategies for entering and leaving modernity]. México City: Grijalbo, 1989. 
CANCLINI, N. G. Hybrid Cultures: Strategies for Entering and Leaving Modernity, Minneapolis: University of Minnesota Press, 1995.

CONTIN, M. I; LARCAMÓN, E. De la Grecia clásica a la Pampa argentina. Revista Museo 8, 1996, p. 9196.

CHEVITARESE, A. L; CORNELLI, G. Religious Syncretism in Mediterranean Hellenistic Culture. Revista de Estudos sobre o Jesus Histórico e sua Recepção. Ano 02, 2009, p. 1-10.

DA MATTA, R. "Você sabe com quem está falando?" Um ensaio sobre a distinção entre indivíduo e pessoa no Brasil, Carnavais, malandros e heróis: para uma Sociologia do dilema brasileiro. Rio de Janeiro, Guanabara, 1990, p. 146-204.

FAORO, R. Os Donos do Poder. Porto Alegre: Editora Globo, 1976.

FOUCAULT, M. Naissance de la biopolitique. Cours au Collège de France, 1978-1979. Paris: Gallimard et Le Seuil, coll. Hautes études (édition établie, sous la direction de François Ewald et Alessandro Fontana, par Michel Senellart), 2004.

FUNARI, P. P. A. Historia Comparada en Iberoamérica: las ciudades españolas y portuguesas en el Nuevo Mundo. Revista de História Comparada. v. 9, 2015, p. 69-87.

FUNARI, P. P. A; FERREIRA, L.; GUILHON ALBUQUERQUE, J. A. Introdução. In: China e Brasil, desafios e oportunidades. São Paulo: Annablume, 2013.

FUNARI, P. P. A. A História em sua integridade: o Centro de Pensamento Antigo e a Base Nacional Comum Curricular. Revista de Estudos Filosóficos e Históricos da Antiguidade, v. 29, 2016, p. 7-12.

FUNARI, P. P. A; GARRAFFONI, R. S. A aculturação como modelo interpretativo: o estudo de caso da Romanização. Revista Heródoto, v. 3, n. 2, Unifesp/Guarulhos, dez. 2018, p. 246-255.

GERMANO, J. W. Estado militar e educação no Brasil (1964-1985). 2 ed. São Paulo: Cortez, 1994.

GERNAOUTI-HÉLIE, S.; DUFOUR, A. De l'ordinateur à la société de l'information. Paris: Presses Universitaires de France, 1999.

GONZALEZ-FERRÍN, E. Cuando fuimos árabes. Córdoba: Almuzara, 2017.

GOSDEN, C. Archaeology and Colonialism. Cambridge: University Press, 2004.

GROSBY, S. Nationalism. Oxford: Oxford University Press, 2005.

GRUZINSKI, S. La pensée métisse. Paris: Fayard, 1999.

GUERRA, A. Notas sobre as perdurações onomásticas pré-romanas no Ocidente Peninsular. In: D’ENCARNAÇÃO, J. et al. (coord). A Lusitânia. Entre Romanos e Bárbaros. Coimbra: Mangualde, 2016. p. 47-69.

HARTOG, F. Régimes d’historicité. Présentisme et expérience du temps. Paris: Le Seuil, 2003.

HEYDENREICH, T. América Latina - lateinisches Amerika? Zur politischen Begriff eines Adjektivs im 19. Jahrhundert. Latein Amerika Studien. 35, 1995, p. 229-245.

HUNG, H-F. China and the transformations of Global Capitalism. Baltimore: John Hopkins, 2009. 
JULIÁ, S. Manuel Azaña: biografía y obras completas. Cahiers de civilisation espagnole contemporaine 2012. [En ligne]. URL: http://journals.openedition.org/ccec/3775; DOI: 10.4000/ccec.3775. Consulté le 21 février 2019.

LAGOPOULOS, A. From sémiologie to postmodernism: A genealogy. Semiótica (Special issue: Part I, On John Deely's Four Ages of Understanding), 178(1/4), 2010, p. 169-253.

LASSÈRE, J-M. Manuel d'épigraphie romaine. Paris: Picard, 2005.

LE ROUX, P.; TRANOY, A. Rome et les indigenes dans le nord-ouest de la Peninsule Iberique. Problèms de épigraphie et d’histoire. Mélanges de la Casa de Velázquez. Tomo 9, 1973, p. 177-231.

MANN, V. B.; GLICK, T. F.; DODDS, \& JERRILYNN, D. Convivencia: Jews, Muslims, and Christians in Medieval Spain. G. Braziller, 1992.

MARTINS, M; CARVALHO, H. As transformações do território: Bracara Augusta e o seu cadastro. Revista de Historiografia, v. 25, 2016, p. 219-243.

MCLUHAN, M. Understanding Media. The Extensions of Man. Londres: Routledge and Kegan Paul, 1964.

MOREIRA, J. A. Literatura portuguesa deixa de ser obrigatória no Brasil. Diário de Notícias. Lisboa, 20/02/2016.

NAVARRO, J. Sociabilidad e historiografía: trayectorias, perspectivas y retos. Saitabi, 56, 2006, p. 99119.

NOGUEIRA, P.; FUNARI, P. P. A.; COLLINS, J. J. (Org.) Identidades fluídas no judaísmo antigo e no cristianismo primitivo. São Paulo: AnnaBlume/FAPESP, 2010, v. 1.

ORTIZ, F. Del fenómeno social de la "transculturación» y de su importancia en Cuba. Tomado de Contrapunteo cubano del tabaco y el azúcar. La Habana: Editorial de Ciencias Sociales, 4, 1983, 8690. Revisado el 17 de Octubre de 2011. http://www.ffo.cult.cu/downloads/ortiz/Del_fenomeno_social_de_la_transculturacion.pdf.

ORY, P. L'Histoire culturelle. Paris : Presse Universitaires de France, 2004.

REDENTOR, A. J. M. A cultura epigráfica no Conventvs Bracaravgvstanvs (Pars Occidentalis). Percursos pela sociedade Brácara da Época Romana. Tese de Doutorado. Universidade de Coimbra, 2011.

REDFIELD, R.; LINTON, R.; HERSKOVITS, M. J. Memorandum for the study of acculturation. American Anthropologist, New Series, v. 38, n. 1, jan./mar. 1936, p. 149-152.

ROMANO, R. American Feudalism. Hispanic American Historical Review, 64, 1984, p. 121-134.

SALAZAR-ACOSTA, M; HOLBROOK, A. Some notes on theories of technology, society and innovation systems for science and technology policy studies (Texto Online).

SCHUMPETER, J. Kapitalismus, Sozialismus und Demokratie. Stuttgart, UTB, 2005 (original de 1942).

SETTIS, S. The future of the 'classical'. Cambridge: Polity Press, 2006.

SILVA, J. T. Eurípedes Simões de Paula (1910-1977). Revista de Historia (USP), v. 160, 2009, p. 17-50.

Hist. R., Goiânia, v. 25, n. 1, p. 40-53, jan/abril 2020 
SIMÕES DE PAULA, E. Marrocos e suas relações com a lbéria na Antiguidade. São Paulo: FFLCH/USP, 1973.

STEWART, R. M. Heidegger and the Intentionality of Language. American Philosophical Quarterly, v. 25, n. 2, 1988, p. 153-162. JSTOR, www.jstor.org/stable/20014234.

WEBSTER, J. Creolizing the Roman provinces. American Journal of Archaeology, 105, 2, 2001, p. 209225.

WECKMANN, L. La herencia medieval del Brasil. México: Fondo de Cultura Económica, 1993.

WECKMANN, L. The Medieval Heritage of Colonial and Modern Mexico. New York: Fordham University Press, 1992.

WOLF, Eric. Europe and the People without History. Berkeley: University of California Press, 1984. 